\title{
Variability of root length density and its contributions to seed yield in chickpea (Cicer arietinum L.) under terminal drought stress
}

\author{
J. Kashiwagi *, L. Krishnamurthy, J.H. Crouch, R. Serraj \\ International Crops Research Institute for the Semi-Arid Tropics, Patancheru, Andhra Pradesh 502324, India \\ Received 10 February 2005; received in revised form 10 February 2005; accepted 12 February 2005
}

\begin{abstract}
The importance of root systems in acquiring water has long been recognized as crucial to cope with drought conditions. This investigation was conducted to: (i) evaluate the variability on root length density (RLD) of chickpea in the vegetative growth stage; (ii) estimate the effect of RLD on seed yield under terminal drought conditions; and (iii) set up a procedure to facilitate the screening of chickpea genotypes with large RLD. Twelve diverse chickpea genotypes were grown in tall PVC cylinders with two different soil water treatments in 2000 and 2001, and in field under water deficit conditions during 2000/2001 and 2001/2002. In field trials, the mean RLD at 35 days after sowing showed a significant positive correlation with seed yield in both years. Similarly, the RLD in the 15-30 cm soil depth had significant positive effects to the seed yield in both years. The importance of the root trait was particularly relevant in 2001/2002, a more severe drought year, when the RLD in deeper soil layer, 30-60 cm depth, showed a significant positive relationship with seed yield. Also, the RLD at deeper soil layer, 30-60 cm depth, was higher in 2001/2002 than in 2000/2001, in particular in tolerant genotypes. The PVC cylinder trials were set up to facilitate the screening of chickpea genotypes with large RLD. RLD of plants grown in cylinders with 70\% field capacity was correlated with RLD in the field trials $(r=0.731 ; p=0.01)$. This work highlights the importance of roots in coping with terminal drought in chickpea. The cylinder system offers a much easier procedure to screen chickpea genotypes with large RLD.

(C) 2005 Elsevier B.V. All rights reserved.
\end{abstract}

Keywords: Chickpea; Root length density; Root profile; Seed yield; Terminal drought

\section{Introduction}

Chickpea (Cicer arietinum L.) is the third most important food legume with a total annual global

\footnotetext{
* Corresponding author. Tel.: +91 4030713327 ; fax: +914030713074

E-mail address: J.Kashiwagi@cgiar.org (J. Kashiwagi).
}

production of $7.5 \mathrm{M}$ tonnes from 10.3 Mha (FAO, 2004). The major chickpea growing areas are in the arid and semi-arid zones. About $90 \%$ of world's chickpea is grown under rain fed conditions (Kumar and Abbo, 2001), where terminal drought is one of the major constraints limiting the productivity. Terminal drought stress is typical of the post-rainy season in the semi-arid tropical regions, where the crop grows and 
matures on a progressively depleting soil moisture profile (Ludlow and Muchow, 1990; Krishnamurthy et al., 1999), determined by rainfall before and during the crop season, evaporative demand, and soil characteristics. Improvements of chickpea yield under drought have been achieved, mostly by breeding short duration cultivars that mature before the water deficit becomes too severe (Kumar et al., 1985; Kumar and Rao, 2001) with a penalty of often not using the available season. Chickpea generally faces varying degrees of terminal drought, and yield stability under these conditions is an important issue for increasing the productivity. Research is, therefore, needed to improve the yield stability under terminal drought conditions.

Breeding and selection for enhanced yield stability and/or potential under drought stress across crop species has shown slow progress and only limited success is evident in a few crops such as rice (Oryza sativa L.), common bean (Phaseolus vulgaris L.) and maize (Zea mays L.) (Fukai and Cooper, 1995; White and Castillo, 1992; Banziger et al., 1999; Schneider et al., 1997). This is partly due to the quantitative and temporal variability in available soil moisture across years, the low genotypic variance in yield under these conditions and inherent methodological difficulties in evaluating component traits (Ludlow and Muchow, 1990) together with the highly complex genetic basis of drought tolerance (Subbarao et al., 1995; Turner et al., 2001). Despite this, it is imperative to identify relevant traits that confer yield stability and/or potential under terminal drought stress (Ludlow and Muchow, 1990). In addition, good characterization of the environment is a prerequisite to enhance the usefulness of any given trait of interest.

The importance of root systems in acquiring water has long been recognized (Miller, 1916). A prolific root system can confer the advantage to support accelerated plant growth during the early crop growth stage and extract water from shallow soil layers that is otherwise easily lost by evaporation (Johansen et al., 1994, 1997). Extracting soil moisture from deeper soil layers can also be an important strategy for such an adaptation. The Vertisols where chickpea is normally grown are characterized by the development of deep soil cracks permitting rapid evaporation from deeper soil layers. Again, prolific root systems may help in maximizing transpiration over the evaporation of deeper soil water under these environments. In fact, many crop varieties with an insufficient root length density below $50 \mathrm{~cm}$ soil depth were shown not to use the sub-soil water to meet their transpiration demand (Subbarao et al., 2000; Passioura, 2002). However, the root system of faba bean fully extracted the sub-soil water with a deeper root system that developed in response to deeper pre-sowing plowing (Joanne and Reid, 1993). Using a crop simulation model, the significance of deep rooting on yield has been studied in various crops. For example, deep root systems in sorghum increased yield by $20 \%$ under drought conditions (Jordan et al., 1983). These results have been confirmed across a number of years and environments in the USA (Sinclair, 1994).

In spite of the recognized importance of roots, a large-scale breeding program for root trait components of drought avoidance has not been conducted largely because of the lack of a reliable, quick, and costeffective screening methodology for phenotyping root traits in multiple environments (Kamoshita et al., 2002). Also, the utility of different root traits needs to be established. In rice, quantitative trait loci (QTL) for rooting depth, root volume and root thickness (diameter) were mapped despite the occurrence of significant $\mathrm{G} \times \mathrm{E}$ interactions (Price and Tomos, 1997; Kamoshita et al., 2002; Price, 2002). In maize, the QTL of primary root length, primary root diameter, primary root weight and adventitious seminal root weight were mapped (Tuberosa et al., 2002). Unfortunately, the limitation for QTL identification of relevant root traits appears to be a large-scale, precise and cost-effective phenotyping. Thus the objectives of this study were: (i) to evaluate the variability of root traits under progressively receding soil moisture conditions; (ii) to assess the relevance of root traits for seed yield in chickpea under receding soil moisture; and (iii) to identify an alternative, simple procedure to screen chickpea genotypes with large roots.

\section{Materials and methods}

\subsection{Plant materials}

Twelve chickpea (C. arietinum L.) genotypes with contrasting growth duration, type (desi or kabuli), growth habits, and responses to drought comprising 
eight cultivated varieties (Annigeri, Chafa, JG 62, KAK 2, Phule G 81-1-1, ICCV 2, JG 74 and K 850), a breeding line (ICCC 42) and three germplasm accessions (ICC 4958, ICC 898, K 1189) were used for all trials conducted. The experiments were conducted at the International Crops Research Institute for the Semi-Arid Tropics, Patancheru, India $\left(17^{\circ} 30^{\prime} \mathrm{N}\right.$; $78^{\circ} 16^{\prime} \mathrm{E}$; altitude $549 \mathrm{~m}$ ).

\subsection{Cylinder trials}

Two experiments using containers were carried out in 2001 and one in 2002. The chickpea plants were grown in PVC cylinders $(18 \mathrm{~cm}$ diameter, $120 \mathrm{~cm}$ height). In 2001, the cylinder trials were carried out in a randomized block design (RBD) with two replications. The experiments were laid on the soil surface in the open field. The cylinders were erected in clusters of four around a single central wooden pillar support. The first experiment was conducted with soils saturated to field capacity (FC) initially and the second with soils uniformly mixed with water required for $70 \%$ of field capacity ( $70 \%$ FC). To decrease the total water held in the containers and to facilitate early onset of drought, equal (w/w) amount of sand was mixed with the Vertisol. The FC cylinders were filled with $27.6 \mathrm{~kg}$ of dry soil-sand mixture, leaving the top $15 \mathrm{~cm}$ empty and irrigated more than the field capacity requirement and allowed to drain. In the $70 \%$ FC experiment, the water holding capacity of the soilsand mixture was calculated. Cylinders were filled with a set amount of soil-sand-water mixture leaving the top $15 \mathrm{~cm}$ empty. To prepare $70 \%$ FC soil, $113 \mathrm{~g}$ of water was required for a kilogram of dry soil. The top $15 \mathrm{~cm}$ of the cylinder was filled with dry soil-sand mixture with di-ammonium phosphate at the rate of $0.07 \mathrm{~g} \mathrm{~kg}^{-1}$. Four seeds of each genotype were sown in the soil-sand mixture on 9th November 2001 in the $70 \%$ FC experiment and on 16th November 2001 in the FC experiment. The cylinders were then irrigated with $500 \mathrm{ml}$ of water immediately after sowing and twice on alternate days with $150 \mathrm{ml}$ until the seedlings uniformly emerged, and later the plants were allowed to grow on progressively receding soil moisture. Immediately after sowing, all cylinders were supplied with a rhizobial inoculum (strain IC 59) as a water suspension. The plants were thinned to two individuals per cylinder at 7 days after sowing (DAS).
In 2002, the PVC trial was similar, except that (i) cylinders were placed in cement pits $(80 \mathrm{~cm}$ width, $120 \mathrm{~cm}$ length and $120 \mathrm{~cm}$ depth) to mimic field growth conditions, with 24 cylinders set in each pit and gaps among cylinders filled with sawdust; (ii) seeds were sown later into the dry season on 26th January 2002; (iii) three plants were grown in each cylinder; (iv) only the 70\% FC soil-sand mixture was applied in 2002 .

\subsection{Field trials}

Two field trials were conducted during the postrainy season, in 2000/2001 and 2001/2002, in a Vertisol field (fine montmorillonitic isohyperthermic typic pallustert). The water holding capacity of this field in lower limit:upper limit was $0.26: 0.40 \mathrm{~cm} \mathrm{~cm}^{-1}$ for the $0-15 \mathrm{~cm}$ soil layer, and $0.30: 0.47 \mathrm{~cm} \mathrm{~cm}^{-1}$ for the $105-120 \mathrm{~cm}$ soil layer. The available soil water up to $120 \mathrm{~cm}$ depth was $165 \mathrm{~mm}$, and the bulk density was $1.35 \mathrm{~g} \mathrm{~cm}^{-3}$ for the $0-15 \mathrm{~cm}$ soil layer and $1.42 \mathrm{~g} \mathrm{~cm}^{-3}$ for the $105-120 \mathrm{~cm}$ soil layer (El-S waify et al., 1985). Before sowing, $18 \mathrm{~kg} \mathrm{~N} \mathrm{ha}^{-1}$ and $20 \mathrm{~kg} \mathrm{P} \mathrm{ha}^{-1}$ as di-ammonium phosphate were applied. A sprinkler irrigation, $20 \mathrm{~mm}$, was applied immediately after sowing to ensure uniform emergence. Subsequently, plants were grown under rain fed conditions. The plots were kept weed free by hand weeding and intensive protection measures were taken against pod borer (Helicoverpa armigera). The field management was the same in both 2000/2001 and 2001/2002 seasons, except that the field was solarized with polythene mulch in the summer preceding the 2001/2002 trial.

In 2000/2001, the root growth and yield evaluation trials were conducted in the same field, sown on 18th October 2000. The trials for root excavation and yield evaluation were grown in adjacent areas of the same field. The individual plot size was $1.5 \mathrm{~m}$ wide $\times 4.0 \mathrm{~m}$ long with 33.3 plants $\mathrm{m}^{-2}$ on a broad-bed furrow in an RBD with three replications. In 2001/2002, a similar design was used; except that the crop was sown on flat seedbed and sowing dates were 29th October for the root growth evaluation trial and 2nd November for the yield evaluation trial. The plot size for the root growth studies was $0.6 \mathrm{~m}$ wide and $2.0 \mathrm{~m}$ long in a RBD with two replications accommodating three rows of plants in a spacing of $20 \mathrm{~cm}$ between rows $\times 15 \mathrm{~cm}$ between 
plants. The plot size for yield evaluation was $1.0 \mathrm{~m}$ wide and $4.0 \mathrm{~m}$ long in a RBD with three replications.

\subsection{Root and shoot sampling}

The roots were sampled at $35 \mathrm{DAS}$, as previous studies indicated that maximum variation in root dry weight (DW) and root length density (RLD) between cultivars is reached at that stage, and that variation is reduced after 41 DAS (Krishnamurthy et al., 1996).

In cylinder trials, the shoots were harvested, and then the roots were washed gently with running water to remove the soil-sand mixture in the cylinders. When approximately three quarters of the soil-sand mixture was washed away, the cylinder was erected gently on a 3-mm sieve so that the entire root system could be removed. The extracted root system was mostly in one piece with very few small segments of detached roots. The roots were thoroughly cleaned and straightened by repeated dipping and rising in buckets of clear water. The length of root was measured from the cotyledonary point to the deepest root tip. In most cases this deepest root corresponded to the taproot. Then, the root system was divided into layers of $15 \mathrm{~cm}$. Root length was measured at each of the $15 \mathrm{~cm}$ depth of the root system, using an image analysis system (WinRhizo, Regent Instruments Inc., Canada) and following a methodology previously described by Serraj et al. (2004). These samples were dried at $80{ }^{\circ} \mathrm{C}$ until constant weights were reached.

In field trials, the shoots were sampled from a $1.5 \mathrm{~m}^{2}$ area $(1.5 \mathrm{~m} \times 1.0 \mathrm{~m}$, width $\times$ length $)$ in $2000 /$ 2001 and $0.45 \mathrm{~m}^{2}$ area $(0.6 \mathrm{~m} \times 0.75 \mathrm{~m})$ in $2001 / 2002$ in one side of each plot after avoiding border effects. Then, soil blocks with $30 \mathrm{~cm} \times 20 \mathrm{~cm} \times 15 \mathrm{~cm}$ (length $\times$ width $\times$ depth) including roots were collected by hammering down rectangular steel templates open at the top and bottom into the soil as per the monolith sampling method in such a way that tap roots of two plants were included. The samples were collected up to $60-\mathrm{cm}$ depth at $15 \mathrm{~cm}$ depth increments in both 2000/2001 and 2001/2002 in each plot as previous studies have indicated that the maximum rooting depth at this stage of crop growth do not exceed 60-cm soil depth (Krishnamurthy et al., 1996). The soil samples containing roots were soaked in water overnight in plastic buckets. A soil watersuspension was made by gently hand crushing the soil clots in buckets filled with water. The roots were then recovered by passing the soil water-suspension through a 2-mm mesh sieve. The root length was measured with the same equipment and method as in the cylinder trial. The shoot DWs were recorded after drying in a hot air oven at $80{ }^{\circ} \mathrm{C}$ for $72 \mathrm{~h}$.

In field experiments, shoot biomass at harvest, seed yield and other yield components were evaluated from an area of $1.5 \mathrm{~m} \times 2.5 \mathrm{~m}$ in 2000/2001 and $1.0 \mathrm{~m} \times 3.5 \mathrm{~m}$ in 2001/2002 after removing the plot border on either end of the plot. The shoots were dried in hot air dryers at $45{ }^{\circ} \mathrm{C}$ for 3 days and DWs were recorded. The shoots were threshed, and the extracted seeds were weighed.

\subsection{Soil water balance model}

Available soil moisture patterns for Vertisol experimental fields in ICRISAT Center during the cropping seasons in 2000/2001 and 2001/2002 were estimated by soil water balance model WATBAL (Keig and McAlpine, 1976). The inputs required for this model are 1 weekly potential evapotranspiration, weekly rainfall (plus irrigation), initial available soil water content and available water holding capacity. The outputs include weekly soil water changes, water surplus, water deficits, actual evapotranspiration and ratio of actual evapotranspiration to potential evapotranspiration. The changes in weekly available soil moisture in the entire soil profile were thus estimated. Such estimations were found to be useful to compare the changes in stored soil water status across years and during the cropping season of particularly Vertisols during the post-rainy season at Patancheru, as the rainfall during this season is usually minimal (Johansen et al., 1994). The changes in stored soil moisture during the two crop seasons are shown in Fig. 2 of Serraj et al. (2004).

\section{Results and discussion}

\subsection{Growth conditions in the field trials}

Weather data over the course of the two experiments are presented in Fig. 1 of Serraj et al. (2004). The significant changes across seasons were lower maximum air temperature and evaporation in year 


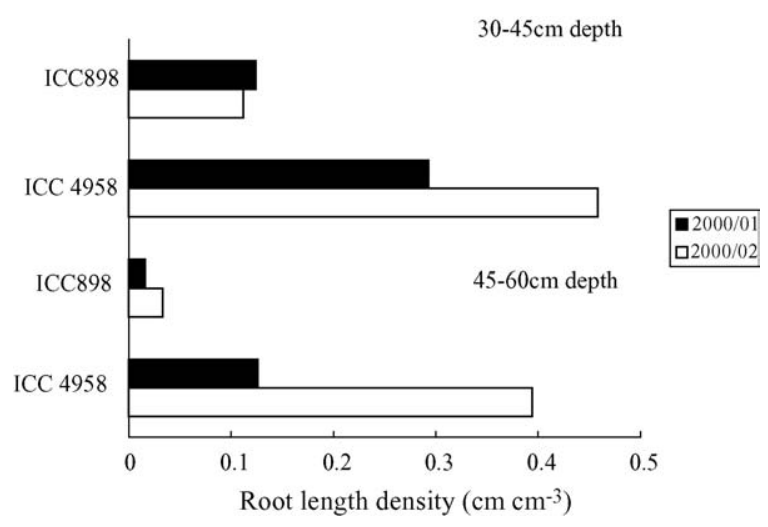

Fig. 1. Difference between ICC 898 and ICC 4958 in RLDs at 30-45 and 45-60 cm soil layers during 2000-2001 and 2001-2002 seasons. ( $L S D=0.03 \mathrm{~cm} \mathrm{~cm}^{-3}$ between years in $30-45 \mathrm{~cm}$ depth, LSD = $0.100 \mathrm{~cm} \mathrm{~cm}^{-3}$ among $\mathrm{G} \times \mathrm{E}$ in $30-45 \mathrm{~cm}$ depth, $\mathrm{LSD}=0.06$ $\mathrm{cm} \mathrm{cm}^{-3}$ between years in $45-60 \mathrm{~cm}$ depth, $=0.194 \mathrm{~cm} \mathrm{~cm}^{-3}$ among $\mathrm{G} \times \mathrm{E}$ in $45-60 \mathrm{~cm}$ depth)

2001/2002, but higher minimum temperature at maturation stages due to a later sowing in the 2001/ 2002 season. There were 16.2 and 4.2 rainfalls just after sowing in 2000/2001 and 2001/2002, respectively, and about $20 \mathrm{~mm}$ rainfall at 76 DAS in 2000/ 2001 season and 70 DAS in 2001/2002 season.

WATBAL simulation showed that available soil water had declined exponentially in both 2000/2001 and 2001/2002 (Serraj et al., 2004, Fig. 2). This indicated that the progression of receding soil moisture was normal and water deficits increased over the seasons. However, the intensity of drought stress, estimated by the soil moisture, was more severe in season 2001/2002 because initial available soil moisture was higher in the 2000/2001 season. This was mainly due to rainfall during the rainy season preceding the 2000/2001 field experiment being about twice the rainfall preceding the 2001/2002 experiment. There was no rainfall during the two cylinder trials.

\subsection{Variability of root length density at 35 DAS in the field and cylinder trials}

In the field experiment, the average root length density at the $0-60 \mathrm{~cm}$ soil profile (RLDtot), varied substantially among the genotypes in both the years (Table 1). The maximum RLDtot was $0.39 \mathrm{~cm} \mathrm{~cm}^{-3}$ for the genotype K 850, closely followed by ICC 4958
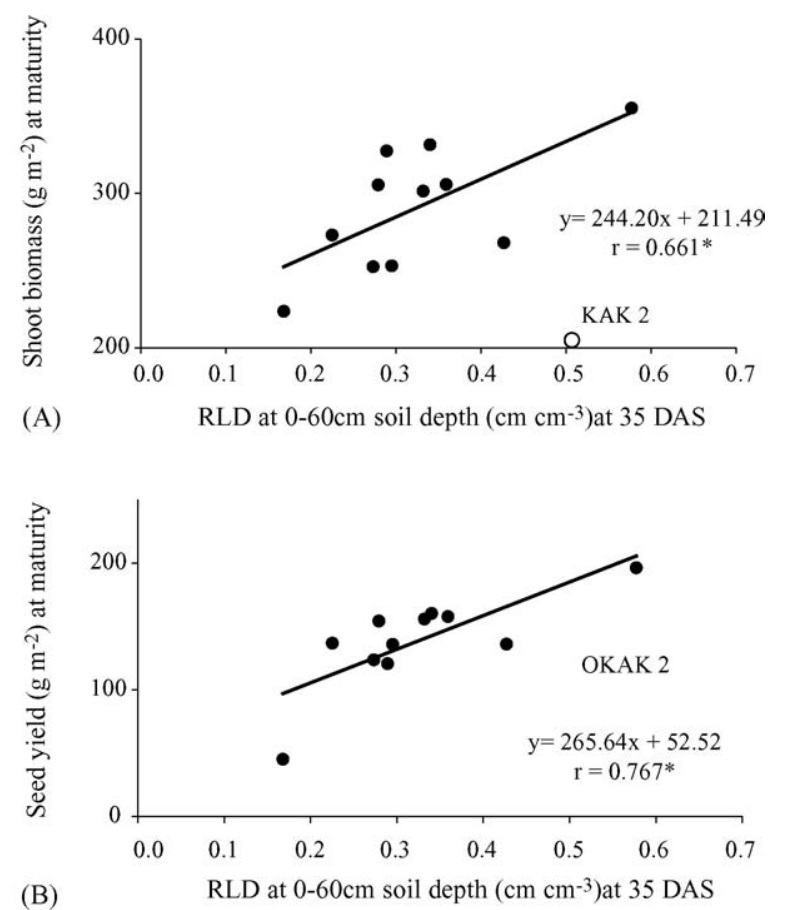

Fig. 2. Relationship between RLD across the rooting profile of field grown chickpea at 35 days after sowing with (A) total shoot biomass at maturity and (B) seed yield of 12 diverse chickpea genotypes grown under terminal drought stress during 2001/2002 post-rainy season (genotype KAK 2 is excluded from both regressions).

$\left(0.38 \mathrm{~cm} \mathrm{~cm}^{-3}\right)$ during the first season and $0.58 \mathrm{~cm} \mathrm{~cm}^{-3}$ for ICC 4958 during the second season (Table 1). Genotype ICC 898, Annigeri, and K1189 had consistently lower RLDtot across seasons, with values ranging from 0.15 to $0.29 \mathrm{~cm} \mathrm{~cm}^{-3}$. The root length density varied between the years and RLDtot was higher in year 2001/2002 $(p<0.02)$ than in 2000/ 2001 (Table 1). In 2001/2002, the genotype ICC 4958 produced an RLDtot of $150 \%$ while that of Annigeri was only $133 \%$ compared to $2000 / 2001$. An RLD of $<0.5 \mathrm{~cm} \mathrm{~cm}^{-3}$ in general (Passioura, 1982), and $<0.4 \mathrm{~cm} \mathrm{~cm}^{-3}$ for chickpea in particular (Gregory, 1988), has been suggested to be sub-optimal for complete extraction of soil moisture. The RLD data found in this work are in agreement with previous work where RLD in chickpea occasionally exceeds $0.5 \mathrm{~cm} \mathrm{~cm}^{-3}$ in a few soil layers even at later stages of crop growth when the maximum root growth has been attained such as 15 days before physiological maturity (Brown et al., 1989; Krishnamurthy et al., 1996; Yusuf 
Table 1

Root length density (RLDtot) and maximum rooting depth (RDp) at 35 days after sowing of 12 chickpea genotypes in field and cylinder trials during 2000-2001 and 2001-2002 post-rainy seasons

\begin{tabular}{|c|c|c|c|c|c|c|c|c|}
\hline \multirow[t]{3}{*}{ Genotype } & \multicolumn{5}{|c|}{ RLDtot $\left(\mathrm{cm} \mathrm{cm}^{-3}\right)$} & \multicolumn{3}{|c|}{$\mathrm{RDp}(\mathrm{cm})$} \\
\hline & \multicolumn{2}{|l|}{ Field } & \multicolumn{3}{|c|}{ Cylinder } & \multicolumn{3}{|l|}{ Cylinder } \\
\hline & $00-01^{\mathrm{a}}$ & $01-02^{b}$ & $\mathrm{FC} 01^{\mathrm{c}}$ & $70 \%{\mathrm{FC} 01^{\mathrm{d}}}$ & $70 \% \mathrm{FC} 02^{\mathrm{e}}$ & FC 01 & $70 \%$ FC 01 & $70 \% \mathrm{FCO} 2$ \\
\hline Annigeri & 0.21 & 0.28 & 0.53 & 0.39 & 0.30 & 116.5 & 103.0 & 108.5 \\
\hline ICC 4958 & 0.38 & 0.58 & 0.57 & 0.57 & 0.42 & 87.0 & 105.5 & 120.0 \\
\hline JG 74 & 0.26 & 0.27 & 0.27 & 0.45 & 0.36 & 108.0 & 126.0 & 115.0 \\
\hline ICCC 42 & 0.31 & 0.36 & 0.27 & 0.35 & 0.31 & 80.5 & 102.0 & 105.5 \\
\hline Phule G81-1-1 & 0.33 & 0.43 & 0.24 & 0.46 & 0.28 & 107.5 & 106.5 & 112.0 \\
\hline Chafa & 0.30 & 0.33 & 0.40 & 0.59 & 0.32 & 104.0 & 113.0 & 117.0 \\
\hline K 850 & 0.39 & 0.34 & 0.43 & 0.63 & 0.43 & 102.0 & 105.5 & 121.5 \\
\hline K 1189 & 0.21 & 0.29 & 0.26 & 0.34 & 0.25 & 102.5 & 92.0 & 96.5 \\
\hline ICCV 2 & 0.37 & 0.30 & 0.40 & 0.39 & 0.35 & 96.5 & 92.4 & 122.5 \\
\hline ICC 898 & 0.15 & 0.17 & 0.32 & 0.41 & 0.23 & 110.5 & 103.4 & 98.5 \\
\hline JG 62 & 0.30 & 0.23 & 0.33 & 0.44 & 0.24 & 101.5 & 89.4 & 119.5 \\
\hline KAK 2 & 0.28 & 0.51 & 0.30 & 0.67 & 0.36 & 113.0 & 96.0 & 109.0 \\
\hline Mean & 0.29 & 0.34 & 0.36 & 0.47 & 0.32 & 102.5 & 102.9 & 112.1 \\
\hline$F$ (predicted) & 0.031 & 0.002 & 0.047 & 0.037 & 0.045 & 0.178 & 0.293 & 0.719 \\
\hline $\mathrm{LSD}_{0.05}$ & 0.14 & 0.14 & 0.20 & 0.19 & 0.12 & - & - & - \\
\hline
\end{tabular}

The soil layers $0-60 \mathrm{~cm}$ in the field and $0-120 \mathrm{~cm}$ in the cylinder were considered for the calculation.

a 2000-2001 post-rainy season.

b 2001-2002 post-rainy season.

c $100 \%$ field capacity soil water treatment in 2001 .

d $70 \%$ field capacity soil water treatment in 2001 .

e $70 \%$ field capacity soil water treatment in 2002 .

Ali et al., 2002). However, under optimally irrigated conditions, the RLD in some soil layers was $>0.5 \mathrm{~cm} \mathrm{~cm}^{-3}$ (Yusuf Ali et al., 2002).

Relatively higher RLDtot production in 2001/2002 was also reflected in the shoot dry weight (SDW) in 2001/2002 and could be explained as a result of soil solarization in this year (Table 2). An enhanced root and shoot growth at 35 DAS in 2001/2002, leading to better soil moisture extraction, is a likely response to the solarization prior to the second season trial. Soil solarization is known to increase soil fertility, minimize weed competition and reduce wilt and other disease incidences (Stapleton et al., 1985; Chauhan et al., 1988). The shoot biomass at 35 DAS performance was closely related to the root biomass production at this stage. The correlation coefficient of RLDtot versus SDW was $0.810(p<0.01)$ and $0.940(p<0.01)$ in the first and second seasons, respectively.

In the cylinder trials there was also large variability among the genotypes across years for RLD, either in the two $70 \%$ FC or in the FC experiments (Table 1). The RLDtot in the cylinder trials tended to be higher than in the field experiments. Also, the maximum rooting depth was $>120 \mathrm{~cm}$ in some genotypes. This is likely to be due to a lower bulk density (1.1) in the PVC cylinders, than in the field (about 1.1-1.4). In the cylinders, genotype ICC 4958 and K850 had consistently higher RLD in the 70\% FC treatment (Table 1). By contrast, genotypes Annigeri and K1189 had consistently lower RLD in the $70 \%$ FC treatment. Root depth (RDp) did not vary significantly between genotypes (Table 1).

Since an important objective of this study is to facilitate screening for large root system and avoid the tedious work of sampling roots in the field, we assessed the correlation between RLDtot in PVC cylinders and those obtained from the field. There was usually good correlation between RLDtot in the field and RLDtot in the PVC cylinders with 70\% FC, except between RLDtot in 2000/2001 in the field trial and RLDtot in 70\% FC in 2000/2001 (Table 3). There was also a significant correlation between the RLDtot of field trials across years, and also between RLDtot across year in the $70 \%$ FC treatment in cylinder trials 
Table 2

Shoot dry weight (SDW) at 35 days after sowing for 12 chickpea genotypes in field and cylinder trials during 2000-2001 and 2001-2002 postrainy seasons

\begin{tabular}{|c|c|c|c|c|c|}
\hline \multirow[t]{3}{*}{ Genotype } & \multicolumn{5}{|c|}{ SDW $\left(\mathrm{g} \mathrm{m}^{-2}\right)$} \\
\hline & \multicolumn{2}{|l|}{ Field } & \multicolumn{3}{|l|}{ Cylinder } \\
\hline & $00-01^{\mathrm{a}}$ & $01-02^{\mathrm{b}}$ & $\overline{\mathrm{FC} 01^{\mathrm{c}}}$ & $70 \%{\mathrm{FC} 01^{\mathrm{d}}}$ & $70 \%$ FC $02^{\circ}$ \\
\hline Annigeri & 21.1 & 34.1 & 85.2 & 29.9 & 55.9 \\
\hline ICC 4958 & 36.8 & 65.7 & 83.3 & 67.2 & 74.7 \\
\hline JG 74 & 23.6 & 29.4 & 53.3 & 23.8 & 64.4 \\
\hline ICCC 42 & 28.0 & 31.1 & 43.9 & 22.5 & 51.8 \\
\hline Phule G81-1-1 & 26.0 & 41.2 & 47.4 & 43.5 & 51.5 \\
\hline Chafa & 25.2 & 35.2 & 76.9 & 21.4 & 54.0 \\
\hline K 850 & 34.4 & 38.0 & 84.9 & 38.5 & 66.5 \\
\hline K 1189 & 21.8 & 35.1 & 61.2 & 30.0 & 38.5 \\
\hline ICCV 2 & 36.9 & 39.0 & 72.2 & 58.2 & 86.8 \\
\hline ICC 898 & 22.9 & 21.0 & 55.7 & 34.6 & 45.3 \\
\hline JG 62 & 29.3 & 25.3 & 46.6 & 33.3 & 57.4 \\
\hline KAK 2 & 34.1 & 50.6 & 118.1 & 46.8 & 81.2 \\
\hline Mean & 28.3 & 37.2 & 69.1 & 37.5 & 60.6 \\
\hline$F$ (predicted) & $<0.001$ & $<0.001$ & 0.035 & 0.011 & 0.025 \\
\hline $\mathrm{LSD}_{0.05}$ & 6.3 & 11.0 & 36.8 & 18.1 & 24.2 \\
\hline
\end{tabular}

a $2000-2001$ post-rainy season.

b 2001-2002 post-rainy season.

c $100 \%$ field capacity soil water treatment in 2001 .

d $70 \%$ field capacity soil water treatment in 2001 .

e $70 \%$ field capacity soil water treatment in 2002 .

(Table 3). By contrast, the RLDtot in the FC cylinder was not correlated with the RLD in any other environment, either the field or the 70\% FC treatment. A pooled analysis of genotypes across all the five environments on RLD exhibited a significant genotype $\times$ environment $(\mathrm{G} \times \mathrm{E})$ interaction $(p=0.007)$. However, the mean square value for the $\mathrm{G} \times \mathrm{E}$ effect was low compared to the mean square value for the genotype effect (data not shown), showing the predominance of a genotypic effect over $\mathrm{G} \times \mathrm{E}$. This indicates that the growth conditions in the PVC cylinders with $70 \%$ FC are close to the field conditions and, therefore, a suitable method to detect genotypic differences for RLD occurring in the field.

Table 3

Correlation coefficients for total root length density (RLDtot) at 35 days after sowing of 12 chickpea genotypes among different environments

\begin{tabular}{lllll}
\hline & Field $00-01^{\mathrm{a}}$ & Field $01-02^{\mathrm{b}}$ & Cylinder FC-01 $^{\text {c }}$ & Cylinder 70\% FC-01 $^{\mathrm{d}}$ \\
\hline Field 01-02 & $0.581^{*}$ & & & \\
Cylinder FC-01 & 0.323 & 0.259 & 0.275 & $0.652^{*}$ \\
Cylinder 70\% FC-01 & 0.444 & $0.577^{*}$ & 0.491 & ${ }^{*}$ \\
Cylinder 70\% FC-02 & $0.731^{\text {e* }}$ & $0.620^{*}$ & \\
\hline
\end{tabular}

\footnotetext{
a 2000-2001 post-rainy season.

b 2001-2002 post-rainy season.

c $100 \%$ field capacity soil water treatment in 2001 .

d $70 \%$ field capacity soil water treatment in 2001 .

e $70 \%$ field capacity soil water treatment in 2002 .

* Significant at $p<0.05$.

** Significant at $p<0.01$.
} 
Table 4

Correlation coefficients among the root length densities (total and layer-wise) at 35 days after sowing and the shoot biomass at maturity (SBM), harvest index (HI), days to maturity (DM) and seed yield (YLD) of 12 chickpea genotypes grown in the field during 2000-2001 and 2001-2002 post-rainy seasons

\begin{tabular}{|c|c|c|c|c|c|c|c|c|}
\hline & $\operatorname{RLD}(0-15)^{\mathrm{a}}$ & $\operatorname{RLD}(15-30)^{\mathrm{b}}$ & $\operatorname{RLD}(30-45)^{\mathrm{c}}$ & $\operatorname{RLD}(45-60)^{\mathrm{d}}$ & RLDtot $^{\mathrm{e}}$ & $\operatorname{SBM}\left(\mathrm{g} \mathrm{m}^{-2}\right)$ & $\mathrm{HI}(\%)$ & DM (days) \\
\hline \multicolumn{9}{|c|}{ 2000-2001 field trial } \\
\hline RLD15-30 & 0.381 & & & & & & & \\
\hline RLD30-45 & -0.024 & $0.645^{*}$ & & & & & & \\
\hline RLD45-60 & 0.059 & $0.684^{*}$ & $0.935^{* *}$ & & & & & \\
\hline RLDtot & 0.532 & $0.883^{* *}$ & $0.797^{* *}$ & $0.838^{* *}$ & & & & \\
\hline $\operatorname{SBM}\left(\mathrm{g} \mathrm{m}^{-2}\right)$ & 0.006 & 0.099 & -0.194 & -0.113 & -0.063 & & & \\
\hline HI (\%) & 0.354 & $0.672^{*}$ & 0.544 & 0.496 & $0.681^{*}$ & -0.090 & & \\
\hline $\mathrm{DM}(\mathrm{d})$ & -0.319 & -0.545 & -0.439 & -0.331 & -0.544 & 0.536 & $-0.784^{* *}$ & \\
\hline YLD $\left(\mathrm{g} \mathrm{m}^{-2}\right)$ & 0.344 & $0.699^{*}$ & 0.406 & 0.405 & $0.613^{*}$ & 0.351 & $0.895^{* *}$ & -0.525 \\
\hline \multicolumn{9}{|c|}{ 2001-2002 field trial } \\
\hline RLD15-30 & $0.854^{* *}$ & & & & & & & \\
\hline RLD30-45 & $0.757^{* *}$ & $0.785^{* * *}$ & & & & & & \\
\hline RLD45-60 & 0.577 & 0.528 & $0.819^{* *}$ & & & & & \\
\hline RLDtot & $0.943^{* *}$ & $0.915^{* *}$ & $0.909^{* *}$ & $0.761^{* *}$ & & & & \\
\hline $\operatorname{SBM}\left(\mathrm{g} \mathrm{m}^{-2}\right)$ & 0.036 & 0.164 & 0.472 & 0.473 & 0.245 & & & \\
\hline $\mathrm{HI}(\%)$ & 0.404 & $0.709^{* *}$ & $0.616^{*}$ & 0.355 & 0.565 & 0.286 & & \\
\hline $\mathrm{DM}(\mathrm{d})$ & -0.381 & $-0.638^{* *}$ & $-0.621^{*}$ & -0.315 & -0.527 & -0.053 & $-0.812^{* *}$ & \\
\hline YLD $\left(\mathrm{g} \mathrm{m}^{-2}\right)$ & 0.442 & $0.718^{* * *}$ & $0.779^{* *}$ & $0.576^{*}$ & $0.659^{*}$ & $0.682^{*}$ & $0.868^{* *}$ & $-0.642^{*}$ \\
\hline \multicolumn{9}{|c|}{ a Root length density at the $0-15 \mathrm{~cm}$ soil layer. } \\
\hline \multicolumn{9}{|c|}{ b Root length density at the $15-30 \mathrm{~cm}$ soil layer. } \\
\hline \multicolumn{9}{|c|}{ c Root length density at the $30-45 \mathrm{~cm}$ soil layer. } \\
\hline \multicolumn{9}{|c|}{${ }^{\mathrm{d}}$ Root length density at the $45-60 \mathrm{~cm}$ soil layer. } \\
\hline \multicolumn{9}{|c|}{ e Root length density at the $0-60 \mathrm{~cm}$ soil layer. } \\
\hline \multicolumn{9}{|c|}{ * Significant at $p<0.05$} \\
\hline ** Significant at & $<0.01$ & & & & & & & \\
\hline
\end{tabular}

\subsection{Contribution of various rooting zones at 35 DAS to seed yield}

The mean RLDtot of the genotypes observed at 35 DAS was positively correlated with the seed yield at maturity in both seasons (Table 4). A layer-wise analysis of the relationship of RLD with final seed yield revealed that RLD in the $0-15 \mathrm{~cm}$ depth (RLD015 ) was neither correlated to other RLD measures, nor to the yield and yield components. The RLD15-30 showed a close positive association with the seed yield in both seasons $(r=0.699, p<0.05$ in $2000 / 2001$; and $r=0.718, p<0.01$ in 2001/2002). RLD30-45 $(r=0.779, \quad p<0.01)$ and RLD45-60 $(r=0.576$, $p<0.05)$ had showed such association on seed yield only in 2001/2002.

The importance of RLD in the upper soil layer is consistent with similar observations reported in upland rice, where the seed yield has been shown to be linearly related to RLD at $25 \mathrm{~cm}$ soil depth
(Mambani and Lal, 1983) and in chickpea, where RLD in the active root zone is closely related with soil moisture absorption (Gregory, 1988; Krishnamurthy et al., 1999). Rowse and Barnes (1979), through investigations with faba bean by simulation modelling, concluded that the improved nutrient mobility from the upper soil layers combined with increased water extraction through increased rate of root elongation would produce larger yields in years of moderate water stress. Ingram et al. (1995) also reported an association between root mass in the 20$40 \mathrm{~cm}$ soil layer and drought tolerance, although the root characteristics were not strongly related to the seed yield of rice under drought conditions. Since the major part of the soil moisture in the top plow pan layer $(0-30 \mathrm{~cm})$ can evaporate quickly if not utilized by the plants, variation between genotypes for the RLD in the $15-30 \mathrm{~cm}$ soil layer may provide tolerant genotypes more water in the initial stages of crop growth. Rapid utilization of water in the upper layers 
Table 5

Shoot biomass at maturity (SBM), seed yield (YLD), harvest index (HI) and days to maturity (DM) of 12 chickpea genotypes grown in the field during 2000-2001 and 2001-2002 post-rainy seasons

\begin{tabular}{|c|c|c|c|c|c|c|c|c|}
\hline \multirow[b]{2}{*}{ Genotype } & \multicolumn{2}{|c|}{$\operatorname{SBM}\left(\mathrm{g} \mathrm{m}^{-2}\right)$} & \multicolumn{2}{|c|}{$\operatorname{YLD}\left(\mathrm{g} \mathrm{m}^{-2}\right)$} & \multicolumn{2}{|l|}{$\mathrm{HI}(\%)$} & \multicolumn{2}{|c|}{ DM (days) } \\
\hline & $00-01^{\mathrm{a}}$ & $01-02^{\mathrm{b}}$ & $00-01$ & $01-02$ & $00-01$ & $01-02$ & $00-01$ & $01-02$ \\
\hline Annigeri & 267.5 & 305.5 & 134.7 & 154.4 & 50.3 & 49.3 & 93.7 & 84.3 \\
\hline ICC 4958 & 284.4 & 355.2 & 144.0 & 196.6 & 50.7 & 55.4 & 89.3 & 84.7 \\
\hline JG 74 & 309.9 & 252.4 & 153.3 & 123.7 & 49.6 & 49.3 & 100.3 & 90.0 \\
\hline ICCC 42 & 310.4 & 305.8 & 166.0 & 157.9 & 53.6 & 51.5 & 99.7 & 93.7 \\
\hline Phule G81-1-1 & 277.9 & 267.9 & 138.8 & 136.3 & 50.0 & 50.8 & 89.0 & 86.7 \\
\hline Chafa & 307.2 & 301.5 & 160.6 & 156.1 & 52.2 & 51.1 & 90.7 & 83.7 \\
\hline K 850 & 336.0 & 331.5 & 151.0 & 160.4 & 45.0 & 49.2 & 113.3 & 108.7 \\
\hline K 1189 & 258.9 & 327.4 & 47.3 & 120.8 & 18.3 & 34.5 & 108.3 & 101.3 \\
\hline ICCV 2 & 203.7 & 253.0 & 105.7 & 136.0 & 51.9 & 53.5 & 86.3 & 82.0 \\
\hline ICC 898 & 318.0 & 223.5 & 57.0 & 45.2 & 17.8 & 19.8 & 136.3 & 120.0 \\
\hline JG 62 & 265.2 & 273.0 & 118.5 & 137.0 & 43.6 & 50.4 & 103.7 & 95.3 \\
\hline KAK 2 & 244.8 & 204.9 & 113.8 & 132.5 & 46.4 & 49.8 & 89.7 & 85.0 \\
\hline Mean & 282.0 & 283.5 & 124.2 & 138.1 & 44.1 & 47.1 & 100.0 & 92.9 \\
\hline$F$ (predicted) & 0.003 & 0.044 & $<0.001$ & 0.021 & $<0.001$ & $<0.001$ & $<0.001$ & $<0.001$ \\
\hline $\mathrm{LSD}_{0.05}$ & 55.0 & 86.1 & 31.6 & 63.2 & 5.99 & 6.68 & 2.1 & 2.8 \\
\hline
\end{tabular}

by tolerant genotypes may have increased early biomass production, with a cascading effect on deeper root production, as shown by the correlation between RLD15-30 and RLD30-45 in both years. It was particularly important to note that there was a significant correlation between RLD at the deeper layers (30-45 and 45-60 cm) and yield in 2001/2002, when the early growth was larger and presumably causing relatively more drought stress. It suggests that water absorption from the deep soil layer by tolerant genotypes having higher RLDs at those layers significantly contribute to yield. While most genotypes showed either a decreased RLD45-60 in 2001/ 2002, or similar RLD in both years (like Annigeri), ICC4958 had higher RLD in 2001/2002, a year when the shoot growth and the consequent water need was more than in 2000/2001 (Fig. 1).

In 2001/2002, there was a positive linear relationship between RLDtot and shoot biomass at maturity $(r=0.661, p<0.05)$ as well as seed yield $(r=$ $0.767, p<0.01)$ when KAK 2 , a kabuli variety, was excluded from the regression analysis (Fig. 2). The yield potential of kabulis are known to be considerably lower than that of the desi varieties (Kumar and Abbo, 2001); therefore, a large-seeded, extra-early KAK 2 had a large root system but not a matching shoot biomass.
In both seasons, earlier maturing genotypes had greater seed yield $(r=-0.525$ in $2000 / 2001$, and $r=-0.642, \quad p<0.01$ in 2001/2002) (Table 4). RLD15-30 exhibited a positive association with harvest index in both seasons $(r=0.672, p<0.05$ in 2000/2001; and $r=0.709, p<0.01$ in 2001/2002), while no such relationship could be detected with SBM that is inclusive of seed yield (Table 4). In 2001/ 2002, when the early growth was relatively higher (Table 2), RLD30-45 also had a positive relationship with harvest index (Table 4), indicating the likely consequence of better early root distribution helping to maintain better partitioning into the grain at the later growth stage under terminal drought conditions leading to better yield stability. However, the effect of a deep and prolific root system on better partitioning into grain needs further study.

\subsection{Variability of the yield and yield components at maturity in field grown chickpea}

Medium duration genotypes such as ICCC 42 , JG 74 and K 850 and the late duration genotype ICC 898 produced some of the highest shoot biomass in 2000/ 2001, whereas the early duration genotypes such as ICC 4958, and Annigeri and medium duration 
genotypes such as $\mathrm{K} 850$ and ICCC 42 produced the highest shoot biomass in the 2001/2002 (Table 5). The early sowing during the 2000/2001 season permitted a longer growth duration of all genotypes, whereby the medium and longer duration genotypes could express their potential to some extent in dry matter production. The seed yield of early duration genotypes (Chafa and ICC 4958) and the yield of some medium duration genotypes (ICCC 42, JG 74 and K 850) was high in the 2000/2001, while the yield of the early genotype ICC 4958 was high in 2001-2002. In general, genotypes ICC 898 and K1189 of the late duration group exhibited a poor harvest index. Chickpea is adapted to cool-season environments. Higher day temperatures $\left(>32{ }^{\circ} \mathrm{C}\right)$, as seen in the second week of February in 2001 and third week in 2002, in the current study, are known to have a confounding effect on the plant water deficit and adversely affect the development of reproductive parts (Summerfield et al., 1990; Williams and Saxena, 1991). And thus, the partitioning of those genotypes that started the process of major pod filling after the second week of February was affected.

\section{Conclusions}

Substantial variation in RLDtot or layer-wise RLD at 35 days after sowing was observed among 12 diverse chickpea genotypes. The RLD had relevance to yield under receding soil moisture conditions of a Vertisol in the short duration environments, since genotypes with high RLD produced higher yields under drought. The large variation in root systems within such a small group of genotypes, and the relation between RLD and yield under drought, suggests that an extensive and systematic screening of the chickpea germplasm might offer a promising range of variation in future breeding for RLD. The fact that RLD increased under more severe stress conditions, in particular in more tolerant genotypes, and that RLD at the deeper layer was related to yield only in a more severe drought suggests that the dynamics of root growth under drought conditions might be a key factor to understand the contribution of roots to drought avoidance. The close association of genotypic performance under $70 \%$ FC cylinder with that of the field suggests that the cylinder protocol could be adapted for screening studies of root traits.

\section{Acknowledgments}

This research was partly supported by unrestricted funds from the Japanese government earmarked for drought tolerance research and breeding under the GT-Biotechnology theme of ICRISAT. The authors gratefully acknowledge the statistical advice given by Dr. S. Chandra (Statistics), ICRISAT and the valuable suggestions by $D r$. Vincent Vadez to improve this manuscript and the technical advice provided by Dr. Jagdish Kumar (Chickpea breeding), ICRISAT.

\section{References}

Banziger, M., Edmeades, G.O., Lafitte, H.R., 1999. Selection for drought tolerance increases maize yields across a range of nitrogen levels. Crop Sci. 39, 1035-1040.

Brown, S.C., Gregory, P.J., Cooper, P.J.M., Keatinge, J.D.H., 1989. Root and shoot growth and water use of chickpea (Cicer arietinum) grown in dryland conditions: Effect of sowing date and genotype. J. Agric. Sci. Camb. 113, 41-49.

Chauhan, Y.S., Nene, Y.L., Johansen, C., Haware, M.P., Saxena, N.P., Sardar Singh, Sharma, S.B., Sahrawat, K.L., Burford, J.R., Rupela, O.P., Kumar Rao, J.V.D.K., Sithanantham, S., 1988. Effect of soil solarization on pigeonpea. Bull. 11, ICRISAT, Patancheru, India.

El-Swaify, S.A., Pathak, P., Rego, T.J., Singh, S., 1985. Soil management for optimized productivity under rain fed conditions in the semi-arid tropics. Adv. Soil Sci. 1, 1-64.

FAO, 2004. Production Year Book, 2003. Food and Agricultural Organization of the United Nations (FAO), Rome, Italy. http:// apps.fao.org.

Fukai, S., Cooper, M., 1995. Development of drought-resistant cultivars using physio-morphological traits in rice. Field Crops Res. 40, 67-86.

Gregory, P.J., 1988. Root growth of chickpea, faba bean, lentil, and pea and effects of water and salt stresses. In: Summerfield, R.J. (Ed.), World Crops. Cool-Season Food Legumes. Kluwer Academic Publishers, The Netherlands, pp. 857-867.

Ingram, K.T., Rodriguez, R., Sarkarung, S., Yambo, E.B., 1995. Germplasm evaluation and improvement for dry seeded rice in drought-prone environments. In: Ingram, K.T. (Ed.), Rain Fed Lowland Rice: Agricultural Research for High-Risk Environments. International Rice Research Institute, Los Banos, Phillippines, pp. 55-56.

Joanne, I.R., Reid, J.B., 1993. Root system modification of faba beans (Vicia faba L.), and its effects on crop performance. 2. Role of water stress. Field Crops Res. 33, 197-215.

Johansen, C., Krishnamurthy, L., Saxena, N.P., Sethi, S.C., 1994. Genetic variation in moisture stress of chickpea grown under line-source sprinklers in a semi-arid tropical environment. Field Crop Res. 37, 103-112. 
Johansen, C., Singh, D.N., Krishnamurthy, L., Saxena, N.P., Chauhan, Y.S., Kumar Rao, J.V.D.K., 1997. Options for alleviating moisture stress in pulse crops. In: Asthana, A.N., Masood Ali, (Eds.), Recent Advances in Pulses Research. Indian Society of Pulses Research and Development, IIPR, Kanpur, India, pp. 425442.

Jordan, W.R., Dugas, W.A., Shouse, P.J., 1983. Strategies for crop improvement drought-prone region (Sorghum bicolor, Triticum aestivum, wheat plant breeding). In: Stone, J.F., Willis, W.O. (Eds.), Agricultural Water Management. Elsevier, Amsterdam, pp. 281-299.

Kamoshita, A., Jingxian Zhang, Siopongco, J., Sarkarung, S., Nguyen, H.T., Wade, L.J., 2002. Effect of phenotyping environment on identification of quantitative trait loci for rice morphology under anaerobic conditions. Crop Sci. 42, 255-265.

Keig, G., McAlpine, J.R., 1976. WATBAL: A Computer System for the Estimation and Analysis of Soil Moisture Regimes Form Simple Climatic Data. Technical Memorandum 74/4, second ed. CSIRO Division of Land Use Research, Canferra, Australia.

Krishnamurthy, L., Johansen, C., Ito, O., 1996. Genetic variation in root system development and its implications for drought resistance in chickpea. In: Ito, O., Johansen, C., Adu-Gyamfi, J.J., Katayama, K., Kumar Rao, J.V.D.K., Rego, T.J. (Eds.),Root and Nitrogen in Cropping Systems of the Semi-arid Tropics. Culio Corporation, Tsukuba, pp. 234-250.

Krishnamurthy, L., Johansen, C., Sethi, S.C., 1999. Investigation of factors determining genotypic differences in seed yield of nonirrigated and irrigated chickpeas using a physiological model of yield determination. J. Agron. Crop Sci. 183, 9-17.

Kumar, J., Haware, M.P., Smithon, J.B., 1985. Registration of four short-duration Fusarium wilt-resistant kabuli (Garbanzo) chickpea germplasm. Crop Sci. 25, 576-577.

Kumar, J., Rao, B.V., 2001. Registration of ICCV96029, super early and double podded chickpea fermplasm. Crop Sci. 41, 605-606.

Kumar, J., Abbo, S., 2001. Genetics of flowering time in chickpea and its bearing on productivity in semi-arid environments. Adv. Agron. 72, 107-138.

Ludlow, M.M., Muchow, R.C., 1990. A critical evaluation of traits for improving crop yields in water-limited environments. Adv. Agron. 43, 107-153.

Mambani, B., Lal, R., 1983. Response of upland rice varieties to drought stress. I. Relation between root system development and leaf water potential. Plant Soil 73, 59-72.

Miller, E.C., 1916. Comparative study of root systems and leaf areas of corn and sorghum. J. Agric. Res. 6, 311-332.

Passioura, J.B., 1982. The role of root system characteristics in the drought resistance of crop plants. In: Drought Resistance of Crops with Emphasis on Rice, International Rice Research Institute, Los Banos, Phillippines, 71-82.

Passioura, J.B., 2002. Environmental biology and crop improvement. Funct. Plant Biol. 29, 537-546.

Price, A.H., Tomos, A.D., 1997. Genetic dissection of root growth in rice (Oriza sativa L.). II: mapping quantitative trait loci using molecular markers. Theor. Appl. Genet. 95, 143-152.
Price, A.H., 2002. QTLs for root growth and drought resistance in rice. In: Mohan Jain, S., Brar, D.S., Ahloowalia, B.S. (Eds.), Molecular Techniques in Crop Improvement. Kluwer Academic Publishers, Boston, pp. 563-584.

Rowse, H.R., Barnes, A., 1979. Weather, rooting depth and water relations of broad beans-a theoretical analysis. Agric. Met. 20, 381-391.

Schneider, K.A., Rosales-Serna, R., Ibarra-Perez, F., Cazares-Enriquez, B., Acosta-Gallegos, J.A., Ramirez-Vallejo, P., Wassimi, N., Kelly, J.D., 1997. Improving common bean performance under drought stress. Crop Sci. 37, 43-50.

Serraj, R., Krishnamurthy, L., Kashiwagi, J., Kumar, J., Chandra, S., Crouch, J.H., 2004. Variation in root traits of chickpea (Cicer arietinum L.) grown under terminal drought. Field Crops Res. 88, 115-127.

Sinclair, T.R., 1994. Limits to crop yield? In: Boote, K.J. (Ed.), Physiology and Determination of Crop Yield. ASA, CSSA and SSSA, Madison, pp. 509-532.

Summerfield, R.J., Virmani, S.M., Roberts, E.H., Ellis, R.H., 1990. Adaptation of chickpea to agroclimatic constraints. In: van Rheenen, H.A., Saxena, M.C. (Eds.), Chickpea in the Nineties. ICRISAT, Patancheru, India, pp. 61-72.

Stapleton, J.J., Quick, J., De Vay, J.E., 1985. Soil solarization: Effectes on soil properties, crop fertilization and plant growth. Soil Biol. Biochem. 17, 369-373.

Subbarao, G.V., Chauhan, Y.S., Johansen, C., 2000. Patterns of osmotic adjustment in pigeonpea-its importance as a mechanism of drought resistance. Eur. J. Agron. 12, 239-249.

Subbarao, G.V., Johansen, C., Slinkard, A.E., Rao, R.C.N., Saxena, N.P., Chauhan, Y.S., 1995. Strategies for improving drought resistance in grain legumes. Crit. Rev. Plant Sci. 14, 469523.

Tuberosa, R., Sanguineti, M.C., Landi, P., Giuliani, M.M., Salvi, S., Conti, S., 2002. Identification of QTLs for root characteristics in maize grown in hydroponics and analysis of their overlap with QTLs for grain yield and the field at two water regimes. Plant Mol. Biol. 48, 697-712.

Turner, N.C., Wright, G.C., Siddique, K.H.M., 2001. Adaptation of grain legumes (pulses) to water limited environments. Adv. Agron. 71, 193-231.

Yusuf Ali, Md., Krishnamurthy, L., Saxena, N.P., Rupela, O.P., Jagdish Kumar, Johansen, C., 2002. Scope for genetic manipulation of mineral acquisition in chickpea. Plant Soil 245, 123134.

Williams, J.H., Saxena, N.P., 1991. The use of non-destructive measurement and physiological models of yield determination to investigate factors determining differences in seed yield between genotypes of "desi" chickpeas (Cicer arietinum). Ann. Appl. Biol. 119, 105-112.

White, J.W., Castillo, J.A., 1992. Evaluation of diverse shoot genotypes on selected root genotypes of common bean under soil water deficits. Crop Sci. 32, 762-765. 